\title{
Estimation of Critical Flow Velocity for Collapse of Gas Test Loop Booster Fuel Assembly
}

\author{
Donna P. Guillen \\ Mark J. Russell
}

September 2005

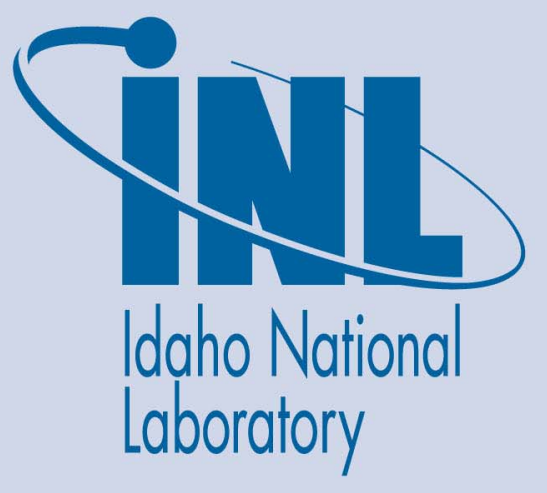

The INL is a U.S. Department of Energy National Laboratory operated by Battelle Energy Alliance 
INL/EXT-05-00788

\title{
Estimation of Critical Flow Velocity for Collapse of Gas Test Loop Booster Fuel Assembly
}

\author{
Donna P. Guillen \\ Mark J. Russell
}

September 2005

\begin{abstract}
Idaho National Laboratory
Idaho Falls, Idaho 83415
\end{abstract}

Prepared for the

U.S. Department of Energy

Under DOE Idaho Operations Office

Contract DE-AC07-05ID14517 


\section{CONTENTS}

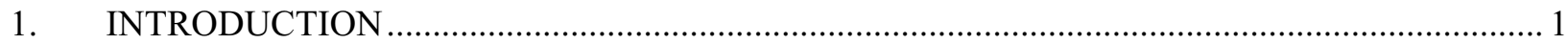

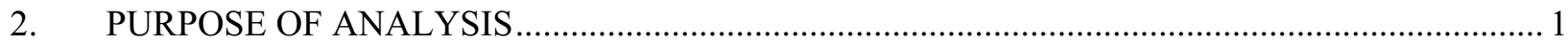

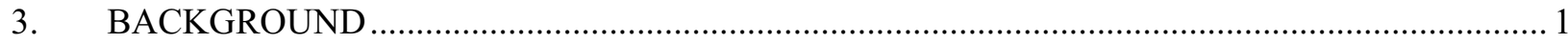

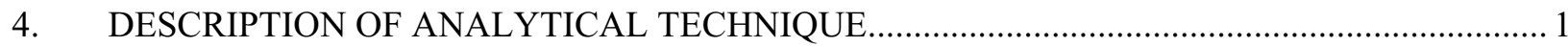

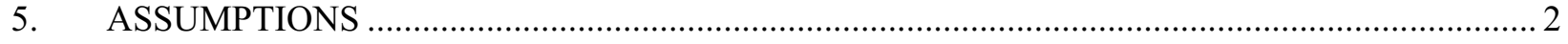

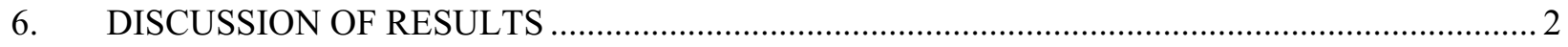

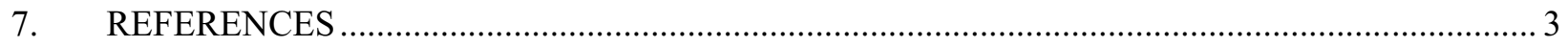

Appendix 


\section{Estimation of Critical Flow Velocity for Collapse of Gas Test Loop Booster Fuel Assembly}

\section{INTRODUCTION}

A Gas Test Loop (GTL) system is currently being designed to provide a high intensity fast-flux irradiation environment for testing fuels and materials for advanced concept nuclear reactors. To assess the performance of candidate reactor fuels, these fuels must be irradiated under actual fast reactor flux conditions and operating environments, preferably in an existing irradiation facility. ${ }^{1}$ The GTL system is being designed for operation in the northwest test lobe of the Advanced Test Reactor (ATR) at the Idaho National Laboratory. The Technical and Functional Requirements (T\&FRs) for the GTL stipulate a minimum neutron flux intensity $\left(10^{15} \mathrm{n} / \mathrm{cm}^{2} \cdot \mathrm{s}\right)$ and fast to thermal neutron ratio $(>15)$ for the test environment. ${ }^{2}$ The incorporation of booster fuel within the test lobe is necessary to achieve these neutron flux requirements. The current design of the booster fuel assembly for the GTL calls for 3 concentric rings of $4 \mathrm{ft}$ long uranium silicide fuel plates clad with 6061 aluminum (see Figure 1 in Appendix).

\section{PURPOSE OF ANALYSIS}

Long parallel plate fuel assemblies can experience static divergence and collapse at sufficiently high coolant flow rates. Such phenomenon has occurred at the Oak Ridge High Flux Reactor ${ }^{3}$ in the 1940 s and the Engineering Test Reactor at the Idaho National Laboratory ${ }^{4}$ in the 1950s. When the coolant flow reaches a critical static divergent velocity, $U_{d}$, parallel plate fuel assemblies will buckle and collapse onto each other as a result of a flow-induced asymmetric pressure distribution in adjacent flow channels. ${ }^{5}$ Analysis was performed herein to determine whether the GTL booster fuel assembly (BFA) could experience plate collapse at the current design flow rates due to a flow-induced static-instability type of failure.

\section{BACKGROUND}

Fuel plate collapse stems from plate deformation, which can be due to turbulence, pressure fluctuations produced by the primary coolant pumps, unequal flow in the channels due to assembly tolerances, etc. Pressure forces act to deflect the fuel plates. Excessive lateral deformation of long parallel plates subject to axial flow can occur due to unbalanced channel pressures when the pressure difference across the plates is too large for the plate to resist. ${ }^{6}$ As the plates deform and the flow channel narrows, the flow velocity increases. By Bernoulli's equation the pressure correspondingly decreases, and this causes an increase of the pressure differential across the plate with a corresponding increase in deformation. This deformation is resisted by elastic restoring forces developed in the plate as a result of the deformation. As the flow velocity reaches the critical velocity, the relationship between pressure, flow and deflection becomes one of positive feedback, so that the pressure increase and lateral deflection increase without any further external increase of fluid flow. This effect can lead to large plate deflections and overheating of the fuel plates given critical fluid velocities.

\section{DESCRIPTION OF ANALYTICAL TECHNIQUE}

The theoretical formulas outlined by Miller (Ref 1), based upon wide-beam theory and Bernoulli's equation, were used for the analysis. Although Miller's theoretical collapse velocity is a simplified model of a complicated system, it remains widely used due to its ease of use in predicting an approximate collapse velocity. ${ }^{6}$ The method is applicable to plates with a length much larger than their width, with their long edges restrained by attachment to side plates, and assembled with uniform spacing. Plate 
assemblies with low aspect ratios, such as those considered here, are prone to lose stability by divergence whereas short, wide plate configurations are prone to flutter. ${ }^{7}$

\section{ASSUMPTIONS}

Assumptions made in the analysis include:

- $\quad$ Fuel plates are uniformly curved with the longitudinal edges hinged (pinned) to rigid side plates. Assuming pinned edge boundary conditions, rather than fixed edges, is conservative (i.e., yields a lower critical velocity) since a more flexible structure exhibits larger deflections in response to a given pressure differential. It is worth pointing out that the actual fuel plates will be attached to the side plates by crimping with a special jig, whereas the mockup fuel plates for the hydraulic flow test will be glued in place. If the hydraulic flow test model is to be used for vibration and/or plate collapse testing, this could affect the results since the boundary conditions are different.

- Coolant flow is incompressible and all channels have the same mass flow, uniform across any plate channel section.

- There is no flow across the channels. This is a conservative assumption since "windows" in the fuel side plates will allow flow between adjacent channels if there is a pressure difference to drive the lateral flow.

- There are no stabilization combs. In practice there will be stabilization combs at the leading and trailing edges (i.e., top and bottom) of the plates that will help steady the fuel plates from flowinduced vibration mechanisms, such as turbulence, vortex shedding and fluid-elastic instability. The presence of the combs will serve to increase the critical velocity.

- $\quad$ Material properties for aluminum are applicable for the plates since the outer surface (fuel cladding) is aluminum and this will dictate the buckling properties.

- This analysis does not include thermal elastic effects, growth of the fuel meat during irradiation, and transverse compressive loadings, which may also impose a negative stiffness on the fuel plates.

\section{DISCUSSION OF RESULTS}

Details of the analysis are included in the Appendix. The theoretical collapse velocity for flat plates with simply supported edges was calculated first. Then, the ratio of the critical velocity of hinged curved plates to that of hinged flat plates was calculated. The critical velocity for the hinged curved plate assembly was calculated by multiplying the predicted collapse velocity for hinged flat plate assemblies by this critical velocity ratio. Due to the higher stiffness of the curved plate assembly, the critical velocity is approximately 15 times higher than that for a long flat plate assembly with identical dimensions.

The predicted plate collapse velocity, $\mathrm{U}_{\mathrm{d}}$, for the GTL booster fuel assembly is $228 \mathrm{~m} / \mathrm{s}(749 \mathrm{ft} / \mathrm{s})$. This would occur at a total coolant flow rate around $9100 \mathrm{gpm}$. Preliminary calculations performed using RELAP5, using a fuel plate surface roughness of 1.31 microns, predict an average coolant flow velocity of approximately $10.5 \mathrm{~m} / \mathrm{s}(34.4 \mathrm{ft} / \mathrm{s})$ with the snubber tube included and $13.4 \mathrm{~m} / \mathrm{s}(44.0 \mathrm{ft} / \mathrm{s})$ without the snubber tube. The total coolant design flow rate without the snubber tube is $533 \mathrm{gpm}$.

Miller (Ref 1) states "in some fuel-plate assemblies collapse has occurred at velocities on the order of one half of the predicted by the formulas here." In the absence of a considerable margin between the 
theoretically predicted plate collapse velocity and the design velocity, a test program would be warranted. However, since the coolant flow velocity is only $6 \%$ of the predicted critical flow velocity based upon Miller's theory, the phenomena of plate collapse due to static instability is unlikely.

\section{REFERENCES}

1. "Justification of Mission Need for the Gas Test Loop," Idaho National Laboratory, INEEL/EXT04-02018, June 2004.

2. Longhurst, G.R., and Khericha, S.T., "Gas Test Loop Technical and Functional Requirements," Draft, Rev. A, Idaho National Laboratory, INEEL/EXT-04-02273, July 2005.

3. Miller, D.R., "Critical Flow Velocities for Collapse of Reactor Parallel-Plate Fuel Assemblies," Journal of Engineering for Power, April 1960, p. 83-95.

4. Stromquist, W.K., and Sisman, O., "High Flux Reactor Fuel Assemblies - Vibration and Water Flow," Report No. ORNL-50, June 15, 1948

5. Doan, R.L., "The Engineering Test Reactor - A Status Report,” Nucleonics, Vol. 16, No. 1, 1958, p. 102-105.

6. Ho, M., Hong, G., and Mack, A.N.F., "Experimental Investigation of Flow-Induced Vibration in a Parallel Plate Reactor Fuel Assembly," $15^{\text {th }}$ Australasian Fluid Mechanics Conference, Sydney, Australia, December 13-17, 2004.

7. Païdoussis, M.P., "Fluid-Structure Interactions: Slender Structures and Axial Flow," Vol. 2, Elsevier Academic Press, New York, 2004, p. 1181-1186. 
Appendix 


\section{APPENDIX}

This calculation applies the method of D. R. Miller (Reference) for calculating the critical flow velocity of collapse to a pinned edge curved plate fuel assembly much like the silicide fuel.

\section{Reference}

D. R. Miller, 1960, "Critical Flow Velocities for Collapse of Reactor Parallel-Plate Fuel Assemblies," Journal of Engineering for Power, April 1960.

Define fuel geometry:

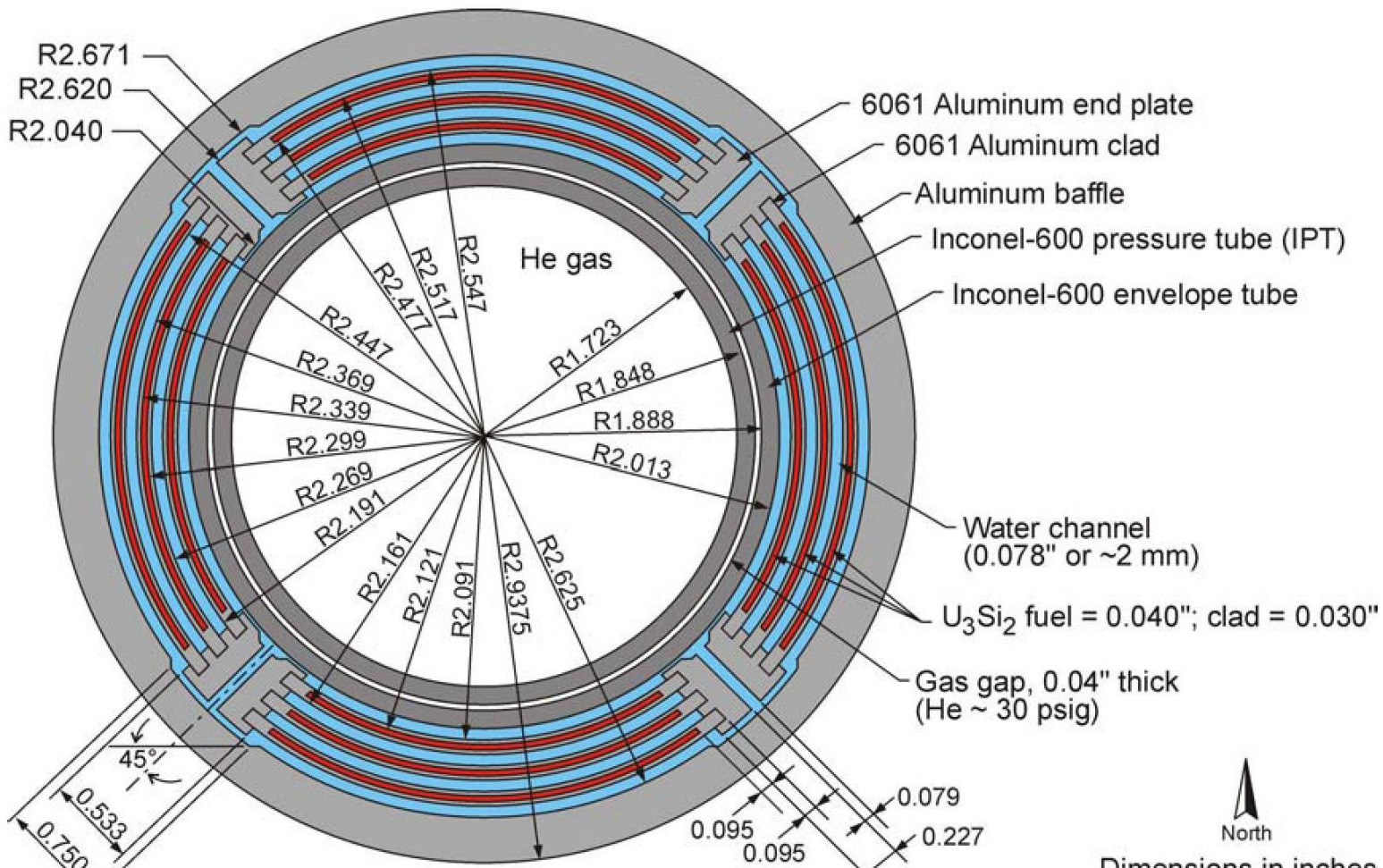

Figure 1. Current booster fuel assembly configuration and dimensions.

$$
\begin{array}{ll}
\mathrm{R}_{\mathrm{O}}:=\left(\begin{array}{l}
2.547 \\
2.369 \cdot \text { in } \\
2.191)
\end{array} \quad \mathrm{R}_{\mathrm{i}}:=\left(\begin{array}{ll}
2.447 \\
2.269 \\
2.091)
\end{array}\right.\right. & \begin{array}{l}
\text { Silicide fuel element plate outer and } \\
\text { inner radii, as of 8/2/2005 [GTL Home } \\
\text { Page, booster fuel assembly, "Revised } \\
\text { Booster Fuel Model }(7 / 18 / 05), \text { Mike } \\
\text { Carboneau, 8/2/2005]. }
\end{array} \\
\mathrm{R}_{\mathrm{o}}-\mathrm{R}_{\mathrm{i}}=\left(\begin{array}{l}
0.1 \\
0.1 \\
0.1
\end{array}\right) & \text { Calculate individual plate thicknesses. } \\
\mathrm{a}:=0.1 \cdot \mathrm{in} & \text { Define plate thickness (Miller, definitions, } \mathrm{p} \mathrm{83).}
\end{array}
$$


Define various fuel plate section parameters on a "per unit width basis".

$\mathrm{w}:=1 \cdot$ in

$\mathrm{A}:=\frac{\mathrm{a} \cdot \mathrm{W}}{\mathrm{W}} \quad \mathrm{A}=0.1$ in

$I:=\frac{\frac{w \cdot a^{3}}{12}}{w}$

$\mathrm{I}=8.333 \times 10^{-5} \mathrm{in}^{3}$

$\mathrm{R}:=\min \left(\frac{\mathrm{R}_{\mathrm{O}}+\mathrm{R}_{\mathrm{i}}}{2}\right) \quad \mathrm{R}=2.141$ in
Arbitrary unit width. Given the discussion on page 85 , where the terms appear in equation (22), I would actually call this variable "unit length".

Area of beam cross section per unit width of beam (Miller, definitions, $p$ 83).

Moment of inertia of beam cross section per unit width of beam (Miller, definitions, $p$ 83).

Radius of curvature of fuel plate. Take the minimum to minimize critical velocity ratio (See Eqn 38 below)

$\alpha:=\frac{\pi}{4}$

Half the curved plate arc between supports (Miller, definitions, p 84).

$$
\begin{aligned}
& \mathrm{C}(\alpha):=\frac{-2}{3}+\sin (2 \cdot \alpha) \cdot\left(\frac{3}{4} \cdot \cot (\alpha)-\alpha\right)-\frac{4}{3} \cdot \cos (2 \cdot \alpha) \ldots \quad \mathrm{C}(\alpha)=0.083 \begin{array}{l}
\text { Miller, Eqn 41, } \mathrm{p} 87 \\
\text { (See definitions, } \mathrm{p} 83 \text { ) }
\end{array} \\
& +\alpha \cdot \cot (\alpha) \cdot\left(1-\frac{\cos (2 \cdot \alpha)}{2}\right)
\end{aligned}
$$

$$
\begin{aligned}
& f_{3}(\alpha):=\frac{1}{2 \cdot \sin (\alpha)^{2}} \cdot\left(\alpha-\frac{3}{4} \cdot \sin (2 \cdot \alpha)+\frac{\alpha \cdot \cos (2 \cdot \alpha)}{2}\right) \quad \text { Miller, Eqn 39, p } 87 \\
& \beta_{2}:=\frac{A \cdot R^{2}}{I} \cdot f_{3}(\alpha)+f_{1}(\alpha) \quad \text { Miller, Eqn 38, p } 87 \\
& \mathrm{~V}_{\mathrm{rh}}:=\left(\frac{8 \cdot \beta_{2} \cdot \sin (\alpha)^{5}}{15 \cdot \mathrm{c}(\alpha)}\right)^{\frac{1}{2}} \quad \mathrm{~V}_{\mathrm{rh}}=14.9
\end{aligned}
$$


Calculate pinned edge velocity to which the above ratio applies.

$g=386.089 \frac{\text { in }}{\sec ^{2}}$

$\mathrm{E}:=10 \cdot 10^{6} \cdot \mathrm{psi}$

$i:=0 . .1$

$\mathrm{h}_{\mathrm{el}_{\mathrm{i}}}:=\mathrm{R}_{\mathrm{i}_{\mathrm{i}}}-\mathrm{R}_{\mathrm{o}_{\mathrm{i}+1}}$

$h:=\min \left(h_{\mathrm{el}}\right)$

$\rho:=62.24 \cdot \frac{\mathrm{lbf}}{\mathrm{ft}^{3}}$

ep $:=0.533 \cdot$ in

$\mathrm{b}:=2 \cdot \alpha \cdot \mathrm{R}-\mathrm{ep}$

$v:=0.33$

$V_{S}:=\left[\frac{5 \cdot g \cdot E \cdot a^{3} \cdot h}{2 \cdot \rho \cdot b^{4} \cdot\left(1-v^{2}\right)}\right]^{\frac{1}{2}}$

$\mathrm{U}_{\mathrm{d}}:=\mathrm{V}_{\mathrm{s}} \cdot \mathrm{V}_{\mathrm{rh}}$

$\mathrm{XA}:=2.50379 \cdot 10^{-3} \cdot \mathrm{m}^{2}$
Gravitational acceleration (Miller definitions, p 83), built-in MathCad variable.

Define Young's Modulus for the fuel plate (Miller definitions, $p$ 83) using room temperature data for aluminum (1000 series) from ASME III, Part D, Subpart 2, Table TM-2.

Range variable for channel thickness calculations

$\mathrm{h}_{\mathrm{el}}=\left(\begin{array}{c}0.078 \\ 0.078\end{array}\right)$ in $\quad$ Fuel element channel widths.

$\mathrm{h}=0.078 \mathrm{in}$

Initial flow channel thickness (minimum, to minimize critical velocity, Miller definitions, p 83).

Weight density of coolant (Miller, definitions, $p$ 84) from RELAP5 calculations.

Dimension of end plate

$b=2.83$ in Width of flat plate (Miller definitions, $p$ 83), taken as arc length of curved plate minus end plate.

Poisson's Ratio of fuel plate (Miller definitions, p 84; taken as that of aluminum from Mark's 8th, Table 3, p 5-5).

$\mathrm{V}_{\mathrm{S}}=50.39 \frac{\mathrm{ft}}{\mathrm{sec}} \quad \begin{aligned} & \text { Critical velocity of pinned edge flat plate, } \\ & \text { Miller, Eqn } 6, \mathrm{p} 84\end{aligned}$

$\mathrm{U}_{\mathrm{d}}=749.2 \frac{\mathrm{ft}}{\mathrm{sec}} \quad \begin{aligned} & \text { Critical static divergent velocity for GTL } \\ & \text { booster fuel assembly. }\end{aligned}$

Total cross-sectional flow area of the four fuel channels. 


$$
\mathrm{Q}:=\mathrm{U}_{\mathrm{d}} \cdot \mathrm{XA}=9.062 \times 10^{3} \mathrm{gpm} \quad \begin{aligned}
& \text { Total coolant flow rate necessary to } \\
& \text { produce plate collapse }
\end{aligned}
$$

